\title{
ESTUDO PILOTO: UM PROCESSO IMPORTANTE DE ADAPTAÇÃO E REFINAMENTO PARA UMA PESQUISA QUASE EXPERIMENTAL EM AQUISIÇÃO DE L2
}

\section{PILOT STUDY: AN IMPORTANT PROCESS IN ADAPTING AND REFINING FOR QUASI-EXPERIMENTAL RESEARCH IN SLA}

\author{
Rafael Zaccaron ${ }^{1}$ \\ Raquel. C. S. F. D'Ely ${ }^{2}$ \\ Donesca C.P. Xhafaj ${ }^{3}$ \\ Universidade Federal de Santa Catarina
}

\begin{abstract}
RESUMO
Com o objetivo de refletir sobre os processos de mudança pelos quais um projeto de pesquisa e um pesquisador iniciante passam ao conduzir estudo piloto, espera-se que o presente trabalho possa somar-se ao corpo de pesquisa em Linguística Aplicada, no caso, o ensino de Inglês como segunda língua no Brasil. Dessa forma, o enfoque dessa análise volta-se para o método, com seus instrumentos e procedimentos, e os dados advindos de um estudo piloto de uma pesquisa de mestrado desenvolvida em um contexto escolar. Por fim, a reflexão sobre esse movimento aponta para benefícios no que toca o refinamento de instrumentos e procedimentos, bem como o amadurecimento do pesquisador que coloca o plano de pesquisa em prática nesse momento. Assim, todos esses processos, do planejamento à análise dos dados do piloto, somam-se a fim de contribuir para que a coleta de dados definitiva ocorra de maneira adequada.
\end{abstract}

PALAVRAS-CHAVE: Estudo Piloto; Planejamento; Planejamento Estratégico; Aquisição de L2.

\begin{abstract}
Reflecting on the adaptation processes that both a research project and a novice researcher go through in conducting a pilot study, the present article aims to contribute to the large body of research in Applied Linguistics and, more specifically, to the field of teaching English as a second language in Brazil. Therefore, the analysis focuses on a pilot study design with its instruments, procedures, and data, originating from the pilot study of a Master's research project, which was carried out in a scholastic context. Ultimately, the reflection of this process indicates benefits, not only in being able to refine the research instruments and procedures, but also, in the maturation of the researcher, who is able to conduct the study at this stage. Thus, all of these processes combined from the planning phase to the data analyses of the pilot project - contribute to assuring the final data collection runs smoothly.

KEYWORDS: Pilot Study; Planning; Strategic Planning; SLA.

\footnotetext{
${ }^{1}$ Mestre em Inglês: Estudos Linguísticos e Literários pelo Programa de Pós-Graduação em Inglês (PPGI) da Universidade Federal de Santa Catarina (UFSC). E-mail: rafaelzaccaron@gmail.com

2 Professora do Departamento de Língua e Literatura Estrangeira (DLLE - UFSC) e do Programa de Pós-Graduação em Inglês da Universidade Federal de Santa Catarina (UFSC). E-mail: raqueldely@gmail.com

3 Professora do Departamento de Língua e Literatura Estrangeira (DLLE - UFSC) da Universidade Federal de Santa
} Catarina (UFSC). Email: donesca@hotmail.com
\end{abstract}




\section{INTRODUÇÃO}

O estudo piloto, também citado como projeto piloto, é definido como um instrumento em pequena escala capaz de reproduzir os meios e métodos planejados para um dado estudo que serão encontrados na coleta de dados definitiva (MACKEY; GASS, 2005; SILVA; OLIVEIRA, 2015). Nas palavras de Bailer, Tomitch, e D’Ely, o estudo piloto é uma “mini versão do estudo completo" (2011: p. 130). Sendo assim, é por meio desse momento na pesquisa que é possível testar a adequação de todos os instrumentos e procedimentos contidos no método com vistas a possibilitar adaptações que se julguem necessárias para a coleta de dados definitiva (CANHOTA, 2008).

Com relação à necessidade ou não de se realizar um estudo piloto, Bailer et al. (2011) afirmam que, apesar de serem tomados todos os possíveis cuidados na fase de planejamento da pesquisa, é no momento do delineamento e implementação do piloto que falhas antes imperceptíveis podem vir à tona, posição essa semelhante à Canhota (2008). Dessa forma, a realização de um projeto piloto para estudos experimentais ou quase-experimentais indica ser uma etapa fundamental para a contribuição no aprimoramento dos mesmos.

Constituindo parte essencial desse trabalho, apresenta-se o referencial teórico, numa breve revisão da literatura. Esses construtos fundamentaram a criação e/ou adequação das escolhas metodológicas e de análise de dados contidas nesse estudo.

Após apresentadas as definições dos conceitos-chave, delineia-se na sequencia o método com detalhamento extensivo do contexto e participantes da pesquisa, dos instrumentos utilizados na coleta e da análise de dados do estudo piloto.

Por fim, foca-se na reflexão das diferentes adequações que foram realizadas para a coleta definitiva, tendo como por base acertos e limitações do estudo piloto. Essa reflexão final constitui o cerne desse trabalho, em outras palavras, o objetivo principal desse artigo é investigar a validade da elaboração e condução do estudo piloto para uma pesquisa na área de Linguística Aplicada. Para alcançar tal objetivo, os seguintes objetivos secundários foram estabelecidos: (1) testar a semelhança das duas tarefas da pesquisa, (2) verificar as condições de planejamento estratégico e o tempo a ser disponibilizado para essa condição e (3) analisar a adequação dos demais instrumentos utilizados.

\section{Revisão da Literatura}

Inserido na área de aquisição de segunda língua ${ }^{4}$, mais especificamente no nicho do ensino baseado em tarefas (ELLIS, 2003, 2005; SKEHAN, 2014), o estudo intitulado "Quanto mais pessoas melhor(?): O impacto do planejamento estratégico individual e colaborativo no desempenho de uma tarefa oral realizada por adolescentes aprendizes de inglês" é uma pesquisa quase experimental de mestrado de cunho quantitativo e qualitativo (DÖRNYEI, 2007). Há quatro conceitos-chave que norteiam esse estudo, sendo eles: planejamento estratégico, atenção, foco-na-forma e planejamento colaborativo em grupos. A seguir, a definição desses conceitos é apresentada.

O planejamento estratégico é uma ação metacognitiva com vistas a facilitar o processamento da linguagem, que, segundo o modelo de processamento linguístico de Levelt (1989) é complexo e demanda tempo e atenção. D’Ely (2006) menciona que aprendizes a quem é dada a oportunidade de planejar estrategicamente antes de executar uma tarefa podem, nesse momento, conceitualizar, formular e auto-monitorar sua fala, o que pode facilitar o processamento linguístico. A atenção, de acordo com Schmidt (2001), é um recurso limitado e seletivo necessário para a aprendizagem. Sobre a atenção, Ortega acrescenta que o sucesso na aprendizagem de uma segunda língua vai "além do que

\footnotetext{
${ }^{4}$ Os autores desse estudo reconhecem a atual vibrante discussão acerca dos termos: língua estrangeira, segunda língua, língua adicional, entre outras, que ocorre nesse momento no Brasil. No entanto, é com base na literatura que dá suporte à esta pesquisa que optou-se pelo termo segunda língua.
}

Revista do GELNE, Natal/RN, Vol. 20 - Número 1: p. 30-41. 2018 
está presente no insumo" (2009, p. 104, tradução nossa) assim, é necessário que se observe aspectos da linguagem. Dessa forma, a atenção é fundamental para o planejamento estratégico. Esse tipo específico de planejamento está fundamentado na ideia de foco-na-forma, um conceito apresentado por Long $(1991,2010)$ que afirma que a atenção aos elementos linguísticos pode acontecer durante a execução de uma tarefa cujo foco principal é no significado. Assim, esse planejamento para executar uma tarefa que pode levar o aluno a prestar atenção na forma tem atraído a atenção dos pesquisadores e profissionais da área. Os resultados de estudos empíricos sobre o planejamento estratégico (D’ELY, 2006; ELLIS, 2003; XHAFAJ; MUCK; D’ELY, 2011, para citar alguns), apontam, em geral, para o impacto positivo dessa condição em diferentes dimensões da performance (acurácia, fluência e complexidade ${ }^{5}$ ) oral.

Além dos conceitos já expostos, é também foco dessa pesquisa o planejamento colaborativo em grupos. Essa condição de trabalho está ancorada na hipótese da produção de Swain (BENISS; BAZZAZ, 2014; SWAIN, 1985; 2001; SWAIN; LAPKIN, 2005), que afirma que aprendizes de uma L2 necessitam manipular elementos linguísticos por meio de diálogos colaborativos (SWAIN, 2000) para que a aquisição da segunda língua ocorra. É através dessa interação que o aprendiz pode vir a prestar atenção nos seus gaps linguísticos e buscar a adequação para sua produção. Com relação aos agrupamentos para interação entre aprendizes, Hyde (1993) fez um estudo qualitativo cujos participantes demonstraram a preferência pelo trabalho em grupos frente ao trabalho individual ou em pares, essa última condição de trabalho sendo a menos preferida. Logo, o presente estudo parte da premissa que o planejamento colaborativo em grupos pode diferir dos resultados obtidos em estudos semelhantes com distribuição em pares.

Em consideração aos estudos de planejamento estratégico, pouca atenção tem sido dada ao planejamento colaborativo, e a maioria dos estudos empíricos com esse enfoque utilizaram o trabalho em pares (BALEGHIZADEH, 2010; FOSTER; OHTA, 2005; STORCH, 2002; XHAFAJ et al.; XHAFAJ, 2013) e não planejamento em grupo ${ }^{6}$. Esses estudos que envolvem trabalho colaborativo também apontam para resultados mistos; embora benefícios tenham sido reportados (STORCH, 2002; XHAFAJ et al., 2011; XHAFAJ, 2013), há pesquisas que apontam para possíveis impactos negativos dessa condição de trabalho (LYNCH e MACLEAN, 2000, 2001). Portanto, mais pesquisas voltadas para tentar elucidar os processos que alunos de uma segunda língua desenvolvem enquanto planejam estrategicamente, em grupos e individualmente, e seu impacto sobre a performance desses alunos são bem-vindas.

Tendo como por base a breve revisão aqui apresentada, o objetivo principal da pesquisa de mestrado é analisar o impacto do planejamento estratégico individual e em grupos no desempenho de uma tarefa oral para alunos adolescentes de Inglês de uma escola pública.

Em consonância com o referencial teórico e o objetivo supracitados, o método da pesquisa e detalhes da coleta de dados do estudo piloto são apresentados na sequência.

\section{Método}

Com o intuito de contextualizar esse recorte da pesquisa de mestrado supracitada apresentam-se as perguntas de pesquisa que guiam o desenho da mesma. Na sequência, os detalhes referentes aos participantes e contexto, instrumentos, bem como o procedimento para a coleta de

\footnotetext{
${ }^{5}$ Acurácia é entendida como a medida que analisa a fala que não apresenta desvios da forma padrão em relação ao uso da fala pelo nativo/a da língua, não em relação à gramática prescritiva. A medida de fluência de acordo com Tavakoli e Skehan (2005) está relacionada à: (1) velocidade, (2) pausas e (3) reparos na fala. Complexidade é uma medida cuja escolha deparâmetro - gramatical ou lexical - tem variado de acordo com diferentes pesquisadores (MICHEL, 2017). Em geral, essa medida aponta o grau de complexidade da fala baseada no parâmetro escolhido.

${ }^{6}$ Para o presente estudo grupo é definido como o agrupamento com mais de dois aprendizes.
} 
dados da pesquisa piloto são detalhados.

\subsection{Perguntas de Pesquisa}

Almejando investigar qual é o impacto do planejamento estratégico colaborativo e individual na performance oral de aprendizes de inglês, quatro perguntas de pesquisa foram elaboradas, sendo elas:

P.1 - O desempenho oral do grupo de planejamento colaborativo é mais fluente, gramaticalmente preciso e adequado do que o desempenho do grupo de planejamento individual? (comparação entre grupos)

P.2 - O desempenho individual oral dos participantes é mais fluente, gramaticalmente preciso e apropriado quando eles planejam em grupos do que quando planejam individualmente? (comparação do desempenho de um mesmo participante em cada uma das condições)

P.3 - Quais estratégias são usadas pelos alunos quando planejam individualmente e de forma colaborativa?

P.4 - Quais é a percepção dos participantes em relação às duas condições distintas de planejamento?

\subsection{Participantes e Contexto}

Dezessete alunos matriculados em um colégio de ensino regular (doravante CER), que é mantido por uma universidade federal como colégio de aplicação, foram convidados e aceitaram participar do estudo (coleta definitiva). O grupo escolhido cursava o segundo ano do Ensino Médio, com idade entre 15 e 17 anos, em 2017. A lógica para a escolha desse grupo é que eles podem ser considerados, em sua maioria, como alunos de nível pré-intermediário/ intermediário de inglês, visto que grande parte desses alunos estudou inglês na escola por mais de cinco anos, e isso pode ajudar a negociação do significado durante o planejamento colaborativo e na subsequente execução da tarefa. Com relação à interação, alunos com níveis de proficiência elevados como observados em Xhafaj et al. (2011) tendem a não negociar durante o planejamento, ao passo que a escolha de alunos com baixa proficiência poderia impor um desafio cognitivo muito elevado para a execução das tarefas escolhidas.

Inicialmente o estudo piloto foi planejado para ocorrer na mesma escola, CER, no fim do ano letivo de 2016. Essa escolha foi baseada no fato de que o estudo piloto deve, preferencialmente, ocorrer com uma população semelhante à da pesquisa definitiva (MACKEY; GASS, 2005). Sendo assim, após aprovação do projeto de pesquisa pelo comitê de ética da $\mathrm{UFSC}^{7}$ e anuência do CER, o primeiro autor começou a assistir em setembro de 2016 as aulas de inglês de uma turma do segundo ano do segundo grau, com a qual havia a intenção de conduzir o estudo piloto. No entanto, em outubro desse mesmo ano, na semana em que os alunos receberiam o Termo de Consentimento Livre e Esclarecido (doravante TCLE) para levar aos pais/responsáveis, ocorreu a ocupação do CER pelos alunos desse colégio para protestar contra a reforma do ensino médio promovida pelo governo federal ilegítimo. Após breve conversa com a professora da turma, decidiu-se que não haveria como se conduzir o piloto até o ano posterior. Dessa forma, os três autores optaram por conduzir o estudo piloto em outra escola da rede pública municipal de Florianópolis.

A escolha dessa segunda escola para a aplicação do estudo piloto foi pautada pelo contato que o primeiro autor possui com o professor de inglês da mesma instituição. Como ambos possuem uma

\footnotetext{
${ }^{7}$ Esse trabalho foi aprovado pelo comitê de ética da UFSC em fevereiro de 2017 sob o seguinte protocolo 1.985.268.
} 
linha pedagógica semelhante, almejou-se que os participantes da pesquisa não percebessem as tarefas do estudo como algo totalmente alheio à sua rotina escolar. Após o termo de anuência assinado pela diretoria da escola, permitindo que a pesquisa do piloto ocorresse nesse local, foi submetida uma emenda ao projeto aprovado pelo comitê de ética para autorizar essa mudança, que finalmente foi aprovada no fim de fevereiro de 2017. Desse modo, o primeiro autor começou a assistir as aulas desse professor em março de 2017 a fim de se familiarizar com os alunos por três semanas. Após esse período, em comum acordo com o professor de inglês dessa escola, foram selecionados seis estudantes para serem convidados a participar da pesquisa. Essa escolha foi pautada no desempenho oral dos mesmos na língua inglesa em sala de aula; era importante que o desempenho dos participantes indicasse que eles tinham possibilidade de executar as tarefas orais propostas no estudo. Esses alunos tinham entre 15 e 17 anos e estudavam na segunda série do Ensino Médio

Os estudantes escolhidos receberam informações, tanto na forma oral como escrita, relacionadas à pesquisa. Foi esclarecido que a participação era completamente voluntária, bem como não haveria remuneração para participação e que a pesquisa ocorreria no horário da aula de inglês em um único encontro. Após o esclarecimento de eventuais dúvidas ${ }^{8}$, foi informado que a pesquisa envolveria o uso de celulares e foram entregues duas cópias do TCLE a cada participante para serem assinadas pela/os responsáveis e pelos participantes, foi também explicado que uma cópia ficaria com eles. Com relação ao TCLE, esse documento foi redigido levando em consideração o público ao qual se dirigia (alunos do Ensino Médio e seus responsáveis), logo, o formato é simplificado sendo ordenado no esquema de perguntas e respostas. Como forma de incentivo para a participação ficou estabelecido que o pesquisador retornaria no segundo semestre de 2017 e proveria um feedback individual para cada participante, o que ocorreu em setembro do mesmo ano, além de um chocolate para cada participante no dia da coleta, incentivo semelhante ao efetuado por Bailer et al (2011). A seguir, há uma breve descrição dos instrumentos da pesquisa.

\subsection{Instrumentos}

Os seguintes instrumentos foram utilizados, tanto no estudo piloto, quanto na pesquisa definitiva: 1) questionário de perfil dos participantes; 2) duas tarefas orais monológicas; 3) protocolo retrospectivo e 4) questionário sobre a percepção das tarefas e as diferentes condições nas quais os aprendizes planejaram as tarefas.

O questionário de perfil continha perguntas gerais relacionadas ao perfil do participante como: idade, período de tempo estudando inglês - na escola e, possivelmente, outra escola de idiomas, possível tempo que tenham passado no exterior em um país de língua inglesa, bem como a motivação dos aprendizes para aprender inglês. Hábitos em relação ao uso dessa língua, dentro e fora de sala de aula, também foram incluídos.

As duas tarefas orais monológicas são adaptadas tendo por base tarefas semelhantes que já foram utilizadas em estudos anteriores (MEHNERT, 1998; XHAFAJ et al., 2011; XHAFAJ, 2013). Ambas as tarefas envolvem planejamento guiado por instruções, e foram realizadas em dois momentos distintos para que todos os participantes trabalhassem sob as duas condições analisadas, ou seja, de forma colaborativa e individualmente, para contrabalancear os efeitos das tarefas.

A tarefa A envolve deixar uma mensagem de voz em inglês para um(a) amigo(a) pelo whatsapp se desculpando pela ausência em uma reunião para fazer um trabalho de escola. Esta mensagem tem de apresentar as seguintes palavras: house, to bring e umbrella (sem ordem específica). Esta tarefa foi adaptada do estudo de Mehnert (1998) e também foi usada nos estudos de Xhafaj et al. (2011) e

\footnotetext{
${ }^{8}$ As dúvidas que puderam ser respondidas. Foi explicado aos participantes que nem todos os detalhes da pesquisa podiam ser conhecidos, já que o conhecimento prévio dos mesmos poderia vir a afetar os dados a serem coletados.
} 
Xhafaj (2013). A tarefa B, adaptada de Xhafaj et al. (2011), segue a mesma estrutura da tarefa A. Para completar a tarefa B, os alunos têm de deixar uma mensagem de voz em inglês pelo whatsapp para um professor se desculpando pelo atraso na entrega de um trabalho. As palavras: bus, to meet e computer precisam aparecer na mensagem (nenhuma ordem específica). O raciocínio para a escolha dessas tarefas é a semelhança com uma situação da vida real que estas tarefas possuem, como apresentado por Long (2000) como também a aceitação positiva pelos participantes demonstrada nos estudos anteriormente aqui citados. Uma diferença dessa pesquisa em relação às demais é o uso do whatsapp, já que o mesmo popularizou-se rapidamente nos últimos anos e recursos como secretária eletrônica, usados nos estudos anteriores, têm caído em desuso.

Com relação ao protocolo retrospectivo, o mesmo foi estruturado na forma de entrevista. As sete perguntas desse protocolo tinham como objetivo tentar elucidar os diferentes processos nos quais os participantes se engajaram enquanto planejavam a tarefa individualmente.

Por fim, o último instrumento, o questionário da tarefa, foi construído para tentar capturar a percepção dos alunos em relação às diferentes condições de planejamento. Este questionário foi adaptado para o presente estudo do questionário desenvolvido por Xhafaj (2013).

\subsection{Procedimento para a coleta de dados - Estudo piloto}

Considerando tanto os parâmetros que norteiam a necessidade de um estudo piloto no que tange a testar instrumentos, quanto o curto espaço de tempo disponível para a coleta após a ocupação do CER, o desenho de coleta de dados da pesquisa definitiva, ver tabela 1, foi adaptado para o piloto na escola pública municipal, ver tabela 2.

Tabela 1: Desenho do estudo coleta principal

\begin{tabular}{|c|c|c|c|}
\hline & $\begin{array}{l}\text { Primeiro } \\
\text { encontro }\end{array}$ & $\begin{array}{l}\text { Segundo encontro } \\
\text { Primeira parte }\end{array}$ & $\begin{array}{l}\text { Segundo encontro } \\
\text { Segunda parte }\end{array}$ \\
\hline Grupo & \multirow{2}{*}{ TCLE } & $\begin{array}{l}\text { planejamento individual tarefa } \mathrm{A} \\
\text { planejamento individual tarefa } \mathrm{B}\end{array}$ & $\begin{array}{l}\text { planejamento em grupo tarefa } \mathrm{B} \\
\text { planejamento em grupo tarefa A }\end{array}$ \\
\hline $\begin{array}{l}\text { Grupo } \\
2\end{array}$ & & $\begin{array}{l}\text { planejamento em grupo tarefa } \mathrm{A} \\
\text { planejamento em grupo tarefa } \mathrm{B}\end{array}$ & $\begin{array}{l}\text { planejamento individual tarefa } \mathrm{B} \\
\text { planejamento individual tarefa } \mathrm{A}\end{array}$ \\
\hline
\end{tabular}

Fonte: Elaborada pelos autores.

Para a coleta de dados do piloto três assistentes de pesquisa foram convidados para participação. Esses assistentes são alunos ou ex-alunos do programa da pós-graduação em inglês da UFSC. Uma sessão de vinte minutos de treinamento sobre os procedimentos da pesquisa foi agendada para os assistentes, essa sessão ocorreu antes da coleta de dados. Nesse momento, cada assistente recebeu uma pasta contendo: uma folha com instruções resumidas para o assistente e os demais instrumentos a serem utilizados na coleta (questionário de perfil, tarefa, folha de rascunho, protocolo retrospectivo e questionário da tarefa). Os assistentes ficaram responsáveis pelos alunos que planejaram individualmente (grupo 1), enquanto o pesquisador permaneceu com os participantes que planejaram de forma colaborativa em grupo (grupo 2). Ver tabela 2:

Tabela 2: Desenho do estudo projeto piloto

\begin{tabular}{|l|l|l|}
\hline & Primeiro encontro & Segundo encontro - Primeira parte \\
\hline
\end{tabular}




\begin{tabular}{|c|c|c|}
\hline $\begin{array}{c}\text { Grupo } \\
1\end{array}$ & & planejamento individual tarefa A \\
\cline { 1 - 1 } $\begin{array}{c}\text { Grupo } \\
2\end{array}$ & TCLE & planejamento em grupo tarefa B \\
\cline { 3 - 3 } & & \\
\hline
\end{tabular}

Fonte: Elaborada pelos autores.

$\mathrm{Na}$ chegada à escola no dia da coleta, o primeiro autor apresentou os assistentes de pesquisa ao diretor da escola e aos participantes, recolheu a via dos TCLE's assinada e pediu para que todos os alunos preenchessem o questionário de perfil. Os alunos foram então informados que a pesquisa ocorreria em duas salas, sendo que três alunos ficariam em cada sala. Participantes 1, 2 e 3 planejaram individualmente a tarefa $\mathrm{A}$, enquanto os participantes 4, 5 e 6 planejaram a tarefa $\mathrm{B}$ em grupo. Os alunos foram direcionados para as respectivas salas onde as instruções para a tarefa foram dadas oralmente em português. Após as instruções e dúvidas sanadas, os alunos tiveram sete minutos para planejar a tarefa, quando eles puderam escrever e fazer anotações enquanto planejavam em folhas fornecidas pelo pesquisador, essas folhas foram posteriormente recolhidas pelo pesquisador e assistentes. A interação do grupo que planejou colaborativamente teve seu áudio gravado usando um gravador de vOz digital Sony Icd-Px440. Faltando dois minutos para esgotar o tempo de planejamento, os participantes nas duas salas, receberam a informação de que eles tinham dois minutos restantes para planejar. E assim que os sete minutos passaram, foi pedido para que os participantes parassem de fazer anotações, deixassem as mesmas de lado e pegassem seus celulares.

Depois disso, os participantes não puderam mais acessar as anotações feitas e foi solicitado que - fora da sala de aula e distante uns dos outros - gravassem a mensagem de áudio da tarefa no whatsapp usando seus telefones móveis ${ }^{9}$. Logo após gravarem a mensagem, os alunos que planejaram individualmente responderam, também individualmente, às perguntas do protocolo retrospectivo gravadas pelos assistentes. Ao retornarem para as salas, todos os participantes preencheram individualmente o questionário sobre a tarefa, que foi recolhido, e cada participante recebeu uma trufa de chocolate.

No que toca aos detalhes da coleta, alguns pontos devem aqui ser mencionados. Em primeiro lugar, o tempo de treinamento para os assistentes mostrou-se inadequado. Durante a coleta os assistentes tiveram dúvidas, sendo que um deles teve que ir à outra sala, onde ocorria o planejamento em grupo, esclarecê-las com o pesquisador duas vezes. Em segundo lugar, uma das participantes do grupo de planejamento individual no momento de planejamento da tarefa decidiu não realizar a mesma; segundo essa participante, a tarefa "pedia mais do que eu sabia e eu fiquei nervosa" em suas palavras. Ressalta-se que a participante, apesar de não gravar a tarefa, quis voluntariamente responder às perguntas tanto do protocolo retrospectivo quanto do questionário da tarefa. Em terceiro lugar, também no grupo de planejamento individual, nenhum dos participantes sabia o significado em português do verbo to bring, uma das palavras obrigatórias a serem incluídas na mensagem. Por fim, observou-se que, de maneira geral, o tempo de sete minutos foi insuficiente para o planejamento da tarefa pelos participantes. Isso ficou evidente por meio da triangulação dos dados provindos do piloto (análise das mensagens, interação em grupo, e questionários sobre a tarefa).

\section{Procedimentos de Análise de Dados}

\footnotetext{
${ }^{9}$ Os participantes foram encorajados a usarem seus próprios celulares para gravarem a mensagem; no entanto, alguns alunos preferiram usar o celular dos assistentes. Ainda sobre o uso de celulares, o pesquisador tinha um chip extra para ser usado somente para essa pesquisa e receber as mensagens, e após o término da coleta o mesmo foi desativado.
} 
As gravações das mensagens usando whatsapp foram transcritas para análise. Inicialmente planejou-se que os dados coletados na pesquisa principal seriam analisados em termos de acurácia, complexidade, fluência e adequação ao gênero, essa última uma variável com viés pragmático. Essa última medida denominada "outcome" foi baseada no trabalho de Farias (2014). Essa análise das mensagens possibilita a comparação entre os resultados das diferentes condições sob as quais os participantes planejaram, ou seja, possibilita responder às duas primeiras perguntas da pesquisa: se o planejamento individual ou em grupos para realizar uma tarefa em inglês possui efeito na produção oral dos estudantes de ensino médio.

Com relação a essa análise das mensagens do estudo piloto, um fato não esperado que ficou perceptível é que, de uma maneira geral, as mensagens gravadas possuíram um baixo nível de complexidade. Esse fato provavelmente deve-se ao gênero ao qual às mensagens de whatsapp pertencem. Mensagens de áudio gravadas usando whatsapp tendem a ser constituídas por frases curtas e isso pôde ser percebido nas gravações dos participantes desse estudo, como na mensagem gravada pela participante 1: "Hi friend. I need of one umbrella. Go, to your house. I'm sick". A análise da variável complexidade previa verificar a quantidade de orações subordinadas presentes nos áudios, mas com base nas mensagens do estudo piloto ponderou-se que essa variável não apresentaria valor significativo para tal análise e, portanto, ela foi suprimida do estudo final..

Os dados qualitativos provindos: (1) das respostas dos participantes aos questionários póstarefa, (2) da transcrição da conversa entre os participantes que planejaram em grupo e (3) do protocolo retrospectivo serviram para validar esses instrumentos, uma vez que as informações esperadas dos mesmos pode ser apreendida. Logo, para a pesquisa final os mesmos foram mantidos.

Em relação aos dados coletados no estudo piloto, devido ao número diminuto da amostra, não foi possível realizar testes estatísticos. Esse fato, no entanto, não tira o mérito dessa análise. $O$ processo de transcrição e segmentação das mensagens de whatsapp gerou algumas dúvidas, por exemplo, como analisar o uso do português nas mensagens. Apesar das instruções para as tarefas explicitarem que as mesmas deveriam ser gravadas em inglês, alguns participantes misturaram o idioma alvo com escolhas lexicais em português. Dessa forma, esse movimento foi positivo, pois serviu como aprendizado, já que o primeiro autor entrou em contato com outros pesquisadores para solucionar dúvidas como essa. $\mathrm{Na}$ sequência, apresentam-se os dados para as variáveis fluência e acurácia, ver tabela 3. Por falta de tempo hábil optou-se por não se realizar a análise da variável pragmática para o estudo piloto.

Tabela 3 - Dados Quantitativos

\begin{tabular}{c|c|c}
\hline Part. & Fluência* & Acurácia** $^{*}$ \\
\hline 1 & 70,9 & 0,75 \\
\hline 2 & 190,59 & 0,33 \\
\hline 4 & 73,3 & 0,5 \\
\hline 5 & 88,42 & 0,14 \\
\hline \multicolumn{3}{|c}{ Fonte: Elaborada pelos autores }
\end{tabular}

* fluência foi medida tendo por base o número total de palavras, divido pelo tempo em segundos

** acurácia foi medida tendo por base o número total de erros, divido número de unidades de AS ${ }^{10}$

Um dos objetivos na realização do estudo piloto para a pesquisa foi determinar se as duas

\footnotetext{
${ }^{10}$ Unidade de AS é uma forma de segmentação de orações que tem se popularizado em estudos de aquisição de L2, por ser uma medida que inclui aspectos que outras medidas, a c-unit por exemplo, desconsideram. Foster, Tonkyn and Wigglesworth definem unidade de AS como "uma segmentação unitária da fala que consiste de uma cláusula independente ou uma sub-cláusula que estejam uma ou a outra associadas com (uma) cláusula(s) subordinada(s) (2000: 365 , tradução nossa).
} 
tarefas eram similares. Essa informação era vital para a utilização ou não dessas duas tarefas no estudo definitivo. Somente quatro mensagens foram avaliadas ${ }^{11}$, porém tendo em vista que não é necessária uma grande amostra para se testar os instrumentos (CANHOTA, 2008), os dados acima cumpriram a função de determinar que apesar de distintas, as duas tarefas são sim similares. Participante 2, que trabalhou com a tarefa A, possuía uma maior fluência (190,59), já os demais participantes mesmo executando tarefas distintas - participante 1 planejou e elaborou a tarefa A, enquanto participantes 4 e 5 trabalharam com a tarefa $\mathrm{B}$ - apresentaram resultados semelhantes para essa variável. Um padrão semelhante foi percebido em relação à acurácia, cujos valores oscilaram entre 0,14 e 0,75 . Sendo assim, tais tarefas se mostraram adequadas para serem usadas como dois estímulos similares, mas diferentes, para a produção oral de aprendizes de inglês como L2.

\section{Conclusões}

O título do presente artigo remete ao processo de adaptação e adequação do desenho de um estudo através da pilotagem de um desenho preliminar elaborado a partir da literatura corrente na área de investigação. Durante a coleta e análise dos dados - e mesmo antes desses procedimentos, na fase de planejamento - foram apresentadas aqui as mudanças pelas quais os instrumentos, aplicação desses e até mesmo alguns aspectos da análise dessa pesquisa passaram. Esse processo assemelha-se ao exposto em Bailer et al. (2011) e a validade desse processo é corroborada por Canhota (2008). Na sequência, apresenta-se um resumo das principais mudanças que o desenho da pesquisa definitiva sofreu a partir dos resultados do estudo piloto.

Apesar de cada aspecto contido no projeto do piloto ter sido cuidadosamente pensado, já antes da coleta ficou evidente que 20 minutos de treinamento para os assistentes não foram suficientes. Para a pesquisa definitiva esse tempo foi acrescido em 15 minutos, totalizando 35 minutos, e dois assistentes que participaram do piloto estavam também presentes na coleta final, fato esse que contribuiu para o sucesso da coleta final. Ainda em relação ao tempo, como já exposto, o tempo de planejamento $(7$ minutos) foi insuficiente. Logo, para a coleta definitiva o tempo de planejamento para cada tarefa foi de 12 minutos, que se mostrou mais adequado às demandas cognitivas exigidas pelas tarefas. Ainda com relação a tempo, o fato dessa pesquisa ter seguido um cronograma estabelecido com tempo alocado a possíveis imprevistos - desde o primeiro momento de submissão do projeto ao comitê de ética - foi determinante para que, mesmo em virtude da ocupação do CER em 2016 e todas as mudanças que esse fato ocasionou à pesquisa, a mesma ocorresse de forma adequada em consonância com o cronograma em 2017.

Em relação às tarefas testadas no estudo piloto, percebeu-se que o verbo em inglês to bring foi um entrave para a execução da mesma. Esse verbo foi trocado por outro verbo semelhante, mas de uso mais difundido - to get para a coleta definitiva. Novamente, essa se mostrou ter sido uma mudança adequada, pois as tarefas não ofereceram, de modo geral, problemas quanto ao significado das palavras obrigatórias para as mensagens durante a coleta no CER.

Com base nos dados quantitativos provindos do piloto, ficou evidente que as mensagens produzidas pelos participantes não possuíam um grau de complexidade compatível para se realizar uma análise dessa variável. Sendo assim, optou-se pela exclusão dessa variável para a análise de dados da pesquisa definitiva.

Afora os já citados benefícios na afinação do método da pesquisa, um ponto de mudança positivo que ficou evidente com a condução do estudo piloto foi a experiência que esse

\footnotetext{
${ }^{11}$ Relembra-se aqui que uma das participantes resolveu parar e não gravar a mensagem. Uma outra mensagem, do participante 6, não foi considerada por não constituir uma desculpa e ser muito curta. Essa última mensagem resumiu-se à somente duas frases com o total de 7 palavras.
} 
procedimento possibilitou a um pesquisador iniciante. $\mathrm{O}$ primeiro autor desse artigo conduz o projeto de pesquisa de mestrado sob a orientação das demais autoras. Para ele, a possibilidade de efetuar uma pesquisa quantitativa e qualitativa como essa tem sido ao mesmo tempo um grande desafio e um enorme aprendizado. E acredito que seja por meio da busca pela excelência na condução desse projeto de pesquisa, seguindo parâmetros rigorosos, que ocorre a maturação de um pesquisador.

Sendo assim, o estudo piloto extrapola a mera função de afinar instrumentos e método. Ele age como catalisador para refinar não somente essas ferramentas, mas também prepara aquele/a que as conduz, já que o/a pesquisador/a terá mais confiança e experiência para conduzir a pesquisa definitiva, e, possivelmente, futuras pesquisas.

\section{CONSIDERAÇÕES FINAIS}

Esse artigo buscou investigar a importância em se planejar e conduzir um estudo piloto. De certa forma, procurou-se responder ao convite feito por Bailer et al. (2011) de se relatar a experiência desse tipo de estudo em artigos, a fim de incentivar futuros pesquisadores a também conduzirem seus estudos piloto. Espera-se também que a presente análise contribua para demonstrar a validade desse movimento em pesquisas experimentais ou quase experimentais no campo da linguística aplicada. O estudo piloto é um importante instrumento para "calibrar" o método, e, porque não, o pesquisador, para o momento da pesquisa definitiva.

\section{REFERÊNCIAS BIBLIOGRÁFICAS}

BAILER, Cyntia; TOMITCH, Leda M. B.; D’ELY, Raquel C. S. F. Planejamento como processo dinâmico: a importância do estudo piloto para uma pesquisa experimental em linguística aplicada. Revista Intercâmbio, v. XXIV: 129-146, 2011. São Paulo: LAEL/PUCSP. ISSN 2237-759x.

BALEGHIZADEH, Sasan. The effect of pair work on a word-building task. ELT Journal. 64 (4), 2010 p.405-413.

BENISS, Aram; BAZZAZ, Vahid. The impact of pushed output on accuracy and fluency of Iranian EFL learners' speaking. Iranian Journal of Language Teaching Research. 2(2), 2014 p. 51-72.

CANHOTA, Carlos. Qual a importância do estudo piloto? In: SILVA, E. E. (Org.). Investigação passo a passo: perguntas e respostas para investigação clínica. Lisboa: APMCG, 2008. p. 69-72.

D'ELY, Raquel C. S. F. A focus on learners' metacognitive processes: the impact of strategic planning, repetition, strategic planning plus repetition, and strategic planning for repetition on L2 oral performance. 2006. Tese (Doutorado em Inglês) - Universidade Federal de Santa Catarina, Florianópolis.

DÖRNYEI, Zoltán. Research Methods in Applied Linguistics: Quantitative, qualitative and mixed methodologies. UK: Oxford University Press, 2007.

ELLIS, Rod. Task-based language learning and teaching. Oxford: Oxford University Press, 2003. 
FARIAS, Priscila. Task-Test: what lies beyond implementing a task-based assessment? Comparing learners' performance and unveiling learners' perception in a testing situation. 2014. Dissertação (Mestrado em Inglês) Universidade Federal de Santa Catarina, Florianópolis.

FOSTER, Pauline; OHTA, Amy S. Negotiation for meaning and peer assistance in second language classrooms. Applied Linguistics, 26 (3), 2005 p. 402-430.

FOSTER, Pauline; TONKYN, Alan; WIGGLESWORTH, Gillian. Measuring Spoken Language: A Unit for All Reasons. Applied Linguistics, 21, 2000, p. 354-75. doi:10.1093/applin/21.3.354.

HYDE, Martin. Pair work - a blessing or a curse?: an analysis of pair work from pedagogical, cultural, social and psychological perspectives. System, Vol. 21, No. 3, 1993 p. 343-348.

LEVELT, Willem J. M. Speaking: From intention to articulation. Cambridge, MA: The MIT Press, 1989. p. 543.

LYNCH, Tony; MACLEAN, Joan. Exploring the benefits of repetition and recycling of a classroom task. Language Teaching Research. n. 4/3 p. 21-250, 2000.

LYNCH, Tony; MACLEAN, Joan. A case of exercising: Effects of immediate task repetition on learners' performance. In: BYGATE, Martin, SKEHAN, Peter, \& SWAIN, Merrill (Eds.), Researching pedagogic tasks second language learning, teaching and testing. Harlow: Pearson Education, 2001. p. 141-162.

LONG, Michael H. Focus on form in task-based language teaching. In: LAMBERT, R. L. and E. SHOHAMY, E. (Eds.), Language policy and pedagogy, 2000 p. 179-192. Amsterdam: Benjamins.

MACKEY, Alison.; GASS, Susan. Common data collection measures. In: Research: methodology and design. Mahwah: Lawrence Erlbaum, 2005. p.43-99. . Second Language

MEHNERT, Uta. The effects of different lengths of time for planning on second language performance. Studies on second Language Acquisition, 20, 1998 p.83-108.

MICHEL, Marije. Complexity, Accuracy and Fluency in L2 Production. In: LOEWEN, Shawn; SATO, Masatoshi. The Routledge Handbook of Instructed Second Language Acquisition. New York: Routledge, 2017 p. 50-68.

ORTEGA, Lourdes. Planning and focus on form in L2 oral performance. Studies in Second Language Acquisition, 1999.

SCHMIDT, Richard. "Attention." In: ROBINSON, Peter (Ed.), Cognition and second language instruction. 2001 p. 3-32. Cambridge University Press.

SILVA, Luis H.; OLIVEIRA, Anna A. S. Contribuições do projeto piloto à coleta de dados em pesquisas na área de educação. Revista Ibero-Americana de Estudos em Educação. v. X, 1: 225-245, 2015. Araraquara: UNESP/Universidad de Alacalá. ISSN 2446-8606.

STORCH, Neomy. Relationships formed in dyadic interaction and opportunity for learning.

Revista do GELNE, Natal/RN, Vol. 20 - Número 1: p. 30-41. 2018 
International Journal of Educational Research. 37: 2002 p. 305-322.

SWAIN, Merrill. Communicative Competence: Some roles of Comprehensible Input and Comprehensible Output in its Development. In: GASS, Susan \& MADDEN, C. (Eds.), Input in second language acquisition. 1985 p. 235-253, Rowley, MA: Newbury House.

SWAIN, Merrill. The output hypothesis and beyond: Mediating acquisition through collaborative dialogue. In: LANTOLF, J. P. (ed.) Sociocultural Theory and Second Language Learning. 2000 p. 97-114). Oxford: Oxford University Press.

SWAIN, Merrill. Integrating language and content teaching through collaborative tasks. The Canadian Modern Language Review, 58 (1), 2001 p. 44-63.

SWAIN, Merrill. LAPKIN, Sharon. The evolving sociopolitical context of immersion education in Canada: Some implications for program development. International Journal of Applied Linguistics, 15(2), 2005 p. 169-18.

TAVAKOLI, Parvaneh, SKEHAN, Peter. Strategic planning, task structure, and performance testing. In R. Ellis (Ed.), Planning and task performance in a second language 2005 p. 239 - 277). Amsterdam: Benjamins.

XHAFAJ, Donesca C. P. MUCK, Kátia E. D'ELY, Raquel C.S.F. The impact of individual and peer planning on the oral performance of advanced learners of English as a foreign language. Linguagem \& Ensino (UCPel. Impresso), v. 14, 2011 p. 39-65.

XHAFAJ, Donesca C. P. One is good, two is better: Investigating the impact of peer-planning in the oral performance of intermediate L2 English learners. 2013. Trabalho de Conclusão de Curso (Letras/Inglês) Universidade Federal de Santa Catarina, Florianópolis.

Recebido em 2/12/2017

Aceito em 17/5/2018 